\title{
ALCOHOL CONSUMPTION AND BODY WEIGHT
}

\author{
MICHAEL T. FRENCH ${ }^{\mathrm{a}, *}$, EDWARD C. NORTON ${ }^{\mathrm{b}}$, HAI FANG $^{\mathrm{c}}$ and \\ JOHANNA CATHERINE MACLEAN ${ }^{\mathrm{d}}$ \\ ${ }^{a}$ Health Economics Research Group, Department of Sociology, Department of Epidemiology and Public Health, and \\ Department of Economics, University of Miami, Coral Gables, FL, USA \\ ${ }^{\mathrm{b}}$ Department of Health Management and Policy, and Department of Economics, University of Michigan, Ann Arbor, MI, USA \\ ${ }^{\mathrm{c}}$ Health Economics Research Group, Department of Sociology, University of Miami, Coral Gables, FL, USA \\ ${ }^{\mathrm{d}}$ Department of Economics, Cornell University, Ithaca, NY, USA
}

\begin{abstract}
SUMMARY
The number of Americans who are overweight or obese has reached epidemic proportions. Elevated weight is associated with health problems and increased medical expenditures. This paper analyzes Waves 1 and 2 of the National Epidemiological Survey of Alcohol and Related Conditions to investigate the role of alcohol consumption in weight gain. Alcohol is not only an addictive substance but also a high-calorie beverage that can interfere with metabolic function and cognitive processes. Because men and women differ in the type and amount of alcohol they consume, in the biological effects they experience as a result of alcohol consumption, and in the consequences they face as a result of obesity, we expect our results to differ by gender. We use first-difference models of body mass index (BMI) and alcohol consumption (frequency and intensity) to control for time-invariant unobservable factors that may influence changes in both alcohol use and weight status. Increasing frequency and intensity of alcohol use is associated with statistically significant yet quantitatively small weight gain for men but not for women. Moreover, the first-difference results are much smaller in magnitude and sometimes different in sign compared with the benchmark pooled cross-sectional estimates. Copyright (C) 2009 John Wiley \& Sons, Ltd.
\end{abstract}

Received 14 June 2007; Revised 22 April 2009; Accepted 8 May 2009

JEL classification: $\mathrm{I}_{12} ; \mathrm{I}_{18} ; \mathrm{H}_{21}$

KEY WORDS: alcohol; body weight; BMI; obesity; fixed-effects

If you are young and you drink a great deal it will spoil your health, slow your mind, make you fat in other words, turn you into an adult.

P.J. O'Rourke

\section{INTRODUCTION}

The number of Americans classified as overweight or obese has increased dramatically over the past two decades. Between 1988 and 2000, the prevalence of being overweight among Americans increased by $40 \%$, and the prevalence of obesity increased by $110 \%$ (Flegal et al., 2002). Recent data indicate that the majority of American adults are now overweight or obese (Flegal et al., 2002, 2005). Although a national increase in weight is not unique to the past two decades (Costa and Steckel, 1995 used historical data to show that weight has risen consistently over the last century), earlier increases were

\footnotetext{
*Correspondence to: Health Economics Research Group, Department of Sociology, Department of Epidemiology and Public Health, and Department of Economics, University of Miami, 5202 University Drive, Merrick Building, Room 121F, P.O. Box 248162, Coral Gables, FL 331284-2030, USA. E-mail: mfrench@miami.edu
} 
generally health enhancing because the national average body mass index (BMI) was below medically recommended levels (Fogel, 1994). Recent weight gains, however, have raised the national average above those levels to the point where further increases generally diminish health status (Cutler et al., 2003).

Obesity and sedentary lifestyles constitute the second leading cause of preventable death in the US and may become the leading cause in the near future (McGinnis and Foege, 1993; Mokdad et al., 2004). Medical research has identified associations between obesity and a range of illnesses (Mokdad et al., 1999; Must et al., 1999). Higher prevalence of chronic diseases among overweight and obese individuals increased health-care costs by an estimated \$117 billion in 2000 (US Department of Health and Human Services, 2001). Lowering the prevalence of obesity to less than $15 \%$ by 2010 is a national health goal (US Department of Health and Human Services, 2001). Nevertheless, our estimates from the National Epidemiological Survey of Alcohol and Related Conditions (NESARC) data suggest that the obesity rate increased from $25 \%$ in 2002 to $29 \%$ in 2005 .

Although many economists would argue that the government's role in influencing body weight should be limited to regulating nutrition labels and providing information about the causes and consequences of weight gain, this position depends upon the absence of externalities. Recent information suggests that large externalities do in fact occur through higher health-care costs and insurance premiums. Total overweight- and obesity-attributable medical spending in 1998 amounted to over $\$ 78$ billion, or $9.1 \%$ of total annual medical expenditures, and half of these expenditures were publicly financed by Medicare and Medicaid (Finkelstein et al., 2003). Rates of obesity are particularly high among minorities and low-income groups (Flegal et al., 2002; Ogden et al., 2006) who may be less likely to self-finance weight-related medical expenses.

Economists have posited several theories to explain the rise in obesity (Cutler et al., 2003; Lakdawalla and Philipson, 2002). Over the past few decades, a number of technological, economic, and social changes have altered income levels and the relative prices of food and exercise. Compared with two decades ago, calories are now less expensive, exercise is more expensive, and income levels are higher. Individuals have responded to these changes in ways that lead to weight gain.

This paper examines one potential contributing factor to weight gain at the individual level: alcohol use. Alcohol is not only an addictive substance; it is a high-calorie beverage that interferes with metabolic function and cognitive processes. Moreover, when consumed to intoxicating levels, alcohol can affect an individual's ability to evaluate the costs and benefits of behaviors such as eating and exercise that affect weight status (Casbon et al., 2003; Field et al., 2005; Hendrie et al., 1996). Because rates of alcohol consumption have remained fairly stable over the last few decades, alcohol use alone cannot explain the general rise in obesity. For certain individuals, however, alcohol use may be an important cause of weight gain - and one that has been overlooked until now.

An accurate measurement of the true relationship between alcohol use and BMI is difficult to obtain with cross-sectional data. Variables that are unobservable to the analyst (such as genetic determinants of body type, preferences, and alcohol tolerance) affect both variables of interest. We therefore eschew cross-sectional data for longitudinal data from the NESARC to sweep away time-invariant omitted variables with first-difference models. Identification of first-difference models rests upon changes in individuals' alcohol use and BMI across the two waves. Fortunately, there is substantial within-person variation in the data. We posit that, ceteris paribus, changes in the frequency and intensity of alcohol use, if large enough, will result in changes in BMI.

\section{CONCEPTUAL FRAMEWORK}

On a purely dietary level, alcohol use would seem to be a contributing factor to individual weight gain due to the high caloric content of most alcoholic beverages. A 12 ounce can of regular beer contains 
approximately 145 calories; a 5 ounce glass of wine, approximately 135 ; and a 1.5 ounce serving of spirits, approximately 130. In addition to its high caloric content, alcohol is a complement for sedentary activities, such as watching television and attending sporting events, which further promote weight gain. Alcohol also stimulates metabolism, which can lead to overeating. One study suggests that the number of people present at a meal is positively correlated with the quantity of food consumed and that the association is stronger when alcohol is involved (de Castro, 2000). In addition, alcohol inhibits the body's ability to burn fat. The liver converts alcohol into acetate, which is released into the bloodstream and used by the body as an energy source. As acetate levels rise, the body begins to burn more acetate and less fat (Leibowitz, 2007; Stewart et al., 2006).

Numerous studies in the clinical and economics literatures show stark gender differences in alcohol consumption and the associated consequences. Men consume more alcohol (Wilsnack et al., 2000), are less likely to abstain (Hupkens et al., 1993), and suffer more consequences as a result of their drinking (Robbins and Martin, 1993). These differences are partially rooted in basic biology. On average, female bodies contain higher amounts of lipids and lower amounts of water than male bodies, so the same amount of alcohol consumed per unit body weight in the same time period results in a higher blood alcohol level in women than in men (Ramchandani et al., 2001). Differences in overall metabolism (Fonda et al., 2004), the pharmacokinetics of alcoholism (Baraona et al., 2001), and the effect of alcoholism on brain volumes (Hommer et al., 2001) are potential biological reasons for women's greater vulnerability to the effects of alcohol. Gender differences in alcohol metabolism have also been identified within the clinical literature. Lieber et al. (Frezza et al., 1990; Lieber, 2000) examined differences in 'first-pass metabolism' of alcohol between men and women. Before alcohol reaches the bloodstream, gastric alcohol dehydrogenase (ADH) isozymes begin the metabolism process in the stomach. Women have relatively lower levels of ADH isozymes than men, leading to reduced metabolism of alcohol in the stomach and higher concentrations of alcohol in the bloodstream. The literature therefore suggests that the biological relationship between alcohol use and body weight differs between women and men.

Non-biological consequences of obesity also differ between women and men. Several studies have found that low body weight and overall physical appearance are significantly related to labor market success for women (e.g. Averett and Korenman, 1996; Cawley, 2003, 2004) but less so for men (French, 2002). A recent study (Robins et al., 2009) re-examined the physical appearance relationships and found that relative to physical attractiveness, personality is a stronger determinant of wages for women, while grooming is more important for men. For both biological and economic reasons, we estimate separate models for men and women, allowing the effect of alcohol use on body weight to differ. ${ }^{1}$

The research literature also suggested two extensions to our basic model. The effect of alcohol use on body weight may be non-linear. Frequent light or moderate alcohol consumption is often associated with lower body weight (Breslow and Smothers, 2005). Those who regularly consume moderate amounts of alcohol are more likely to reduce their intake of other foods to balance the caloric increase from alcohol (Cordain et al., 1997, 2000). High-intensity drinkers (regardless of frequency) may be less likely than other drinkers to reduce their intake of other foods, potentially leading to weight gain (Istvan et al., 1995; Breslow and Smothers, 2005). Alternatively, individuals with alcohol disorders may frequently consume high levels of alcohol but too few calories from other sources to maintain normal weight. With less than $4 \%$ of the US population meeting the clinical definition of alcohol dependence (National Institute on Alcohol Abuse and Alcoholism [NIAAA] website, accessed April 9, 2009), the weight-enhancing effects of high-intensity drinking are likely to dominate the weight-dampening effects of alcohol disorders for most individuals and in the aggregate. These differences suggest that the effect of alcohol use on body weight could be non-linear.

\footnotetext{
${ }^{1}$ Gender-specific models have statistical support as well. Chow tests for differences between men and women are highly significant $(p<0.0001)$ in all cases.
} 
Another extension is to examine the effect of alcohol consumption on body weight at various stages of life. Overall metabolism declines with age, and alcohol metabolism is likely to decline as well. Although little published research examines age differences in the effect of alcohol use on body weight, intuition suggests that the effect of alcohol on body weight increases with age. We therefore estimate separate models for respondents in three age groups: 18-25, 26-50, and 50+.

Guided by this conceptual background and the existing literature, we test four hypotheses: (1) increasing the frequency and intensity of alcohol use has a positive effect on body weight, (2) this effect is greater for women than for men, (3) the relationship between alcohol use and body weight is nonlinear and stronger among high frequency and high-intensity users, and (4) the effect of alcohol use on body weight is greater for older individuals.

One of the pitfalls of using cross-sectional data to estimate the relationships between body weight and alcohol consumption is potential bias due to unobserved (to the analyst) individual heterogeneity. This is especially a concern given recent research that has identified a long list of factors that affect body weight. While the media and public health officials have focused on proximal factors (e.g. television and fast food), economists have generally identified technological and social advances and their associated price changes as the most significant determinants of current weight levels (Chou et al., 2002; Cutler et al., 2003; Lakdawalla and Philipson, 2002; Philipson and Posner, 2003; Ruhm, 2000, 2005; Rashad et al., 2006). Additional economic research has investigated the role of food marketing (Ippolito and Mathios, 1995), habit formation (Naik and Moore, 1996), addiction (Cawley, 1999), and smoking rates (Gruber and Frakes, 2006; Rashad, 2006) in weight differences. For the 3-year time span of our data, these factors are likely to be time-invariant (e.g. genetic determinants of preferences, body type, and alcohol tolerance) or nearly time-invariant (e.g. local markets for food, exercise, cigarettes, alcohol). Because these factors are potentially correlated with both body weight and alcohol use, cross-sectional models may generate biased estimates. To overcome this potential bias, we estimate first-difference models to control for time-invariant individual characteristics. First-difference models should remove most of the bias due to omitted variables that are known to affect caloric intake or output and may also be correlated with alcohol use. Identification rests on within-person changes in both alcohol use and BMI. As shown below, the data present substantial variation in both of these variables.

\section{METHODS}

We first estimate pooled cross-sectional linear regression models to predict BMI as a function of alcohol use and other covariates. We view this specification as a reduced-form BMI production function. Its purpose is to establish a benchmark for the first-difference models despite the longitudinal nature of the NESARC and the potential endogeneity problems. The basic linear specification with pooled crosssectional data is

$$
\mathrm{BMI}_{i t}=\alpha_{0}+\alpha_{1} \text { Frequency }_{i t}+\alpha_{2} \text { Intensity }_{i t}+\alpha_{3} X_{i t}+\mu_{i}+\varepsilon_{i t}
$$

where BMI is body mass index, $i$ indexes individuals, $t$ indexes time, Frequency is a continuous measure of alcohol use frequency (days of drinking alcohol, past year), Intensity is a continuous measure of alcohol use intensity (average number of drinks per episode, past year), $X$ is a vector of control variables, $\mu$ represents unobserved time-invariant individual factors, $\varepsilon$ is a random error, and the $\alpha$ s are coefficients to be estimated.

We test whether alcohol use frequency and intensity affect BMI by examining the coefficients $\alpha_{1}$ and $\alpha_{2}$. Because we do not observe all predictors of BMI, however, the single-equation model will include important omitted variables in the disturbance, $\mu_{i}+\varepsilon_{i t}$. Estimation of single-equation models such as Equation (1) will generate consistent coefficient estimates only if no unobservable omitted variables are correlated with alcohol use (Wooldridge, 2001). Two examples of potentially important omitted variables 
are dieting practices and chronic eating disorders (Gruchow et al., 1985; Goldbloom et al., 1992). Individuals who diet may restrict their alcohol use while chronic overeaters or those with poor impulse control may over-consume alcohol. Without better measures of eating behaviors and other personality traits, the alcohol consumption variables in a single-equation model could be picking up the effects of other behaviors and traits, thereby introducing bias into the coefficient estimates. The direction of the omitted variable bias is theoretically indeterminate because it depends not only on the nature of the omitted variables but also on the correlations among the covariates.

Although one potential way to control for omitted variable bias is by using instrumental variables, finding valid and reliable instruments is often difficult (French and Popovici, 2008). Instrumental variables should be correlated with alcohol use but should not affect BMI directly. Given the inherent challenges associated with a credible IV analysis, and the fact that the NESARC recently completed a second wave, we estimated an individual first-difference model. The first-difference model implicitly controls for time-invariant characteristics. All time-varying variables are entered into the models as change scores. Change scores for the key dependent and explanatory variables have more compact distributions with fewer outliers relative to the cross-sectional distributions (see Table I). Finally, the estimated coefficients have a straightforward interpretation with direct clinical and policy implications (Wooldridge, 2001).

Table I. Summary statistics

\begin{tabular}{|c|c|c|c|c|c|c|}
\hline \multirow[b]{2}{*}{ Variables } & \multicolumn{3}{|c|}{ Men } & \multicolumn{3}{|c|}{ Women } \\
\hline & Wave 1 & Wave 2 & $p$-Value & Wave 1 & Wave 2 & $p$-Value \\
\hline \multicolumn{7}{|l|}{ Body weight variable } \\
\hline Body mass index (BMI) & $\begin{array}{l}27.40 \\
(4.88)\end{array}$ & $\begin{array}{l}27.89 \\
(5.09)\end{array}$ & $<0.01$ & $\begin{array}{l}26.99 \\
(6.30)\end{array}$ & $\begin{array}{l}27.70 \\
(6.60)\end{array}$ & $<0.01$ \\
\hline \multicolumn{7}{|l|}{ Alcohol consumption, past year } \\
\hline Frequency: days of drinking alcohol & $\begin{array}{c}72.99 \\
(106.43)\end{array}$ & $\begin{array}{c}74.01 \\
(105.18)\end{array}$ & 0.42 & $\begin{array}{c}35.08 \\
(77.20)\end{array}$ & $\begin{array}{c}36.99 \\
(76.89)\end{array}$ & 0.02 \\
\hline $\begin{array}{l}\text { Intensity: average number of drinks } \\
\text { per episode (full sample) }\end{array}$ & $\begin{array}{c}2.15 \\
(2.63)\end{array}$ & $\begin{array}{c}2.11 \\
(2.49)\end{array}$ & 0.16 & $\begin{array}{l}1.17 \\
(1.58)\end{array}$ & $\begin{array}{l}1.16 \\
(1.49)\end{array}$ & 0.72 \\
\hline $\begin{array}{l}\text { Intensity: average number of drinks } \\
\text { per episode (drinker) }\end{array}$ & $\begin{array}{c}2.97 \\
(2.67)\end{array}$ & $\begin{array}{c}2.94 \\
(2.49)\end{array}$ & 0.39 & $\begin{array}{c}1.99 \\
(1.62)\end{array}$ & $\begin{array}{l}1.98 \\
(1.47)\end{array}$ & 0.82 \\
\hline No alcohol use $(\%)$ & 27.71 & 28.42 & 0.18 & 40.84 & 40.99 & 0.78 \\
\hline \multicolumn{7}{|l|}{ Demographics and other variables } \\
\hline Household income in $\$ 10000 \mathrm{~s}$ & $\begin{array}{c}5.63 \\
(4.94)\end{array}$ & $\begin{array}{c}6.27 \\
(5.55)\end{array}$ & $<0.01$ & $\begin{array}{c}4.58 \\
(4.47)\end{array}$ & $\begin{array}{c}5.07 \\
(4.88)\end{array}$ & $<0.01$ \\
\hline Number of people in household & $\begin{array}{l}2.55 \\
(1.46)\end{array}$ & $\begin{array}{c}2.69 \\
(1.49)\end{array}$ & $<0.01$ & $\begin{array}{l}2.55 \\
(1.49)\end{array}$ & $\begin{array}{c}2.70 \\
(1.53)\end{array}$ & $<0.01$ \\
\hline SF-12 mental health scale & $\begin{array}{l}53.34 \\
(9.92)\end{array}$ & $\begin{array}{l}53.02 \\
(9.90)\end{array}$ & $<0.01$ & $\begin{array}{c}50.89 \\
(10.84)\end{array}$ & $\begin{array}{c}50.59 \\
(10.67)\end{array}$ & $<0.01$ \\
\hline Age & $\begin{array}{c}45.50 \\
(16.78)\end{array}$ & $\begin{array}{l}48.56 \\
(16.74)\end{array}$ & $<0.01$ & $\begin{array}{c}46.45 \\
(17.75)\end{array}$ & $\begin{array}{c}49.53 \\
(17.69)\end{array}$ & $<0.01$ \\
\hline Years of schooling & $\begin{array}{l}13.30 \\
(3.39)\end{array}$ & $\begin{array}{l}13.37 \\
(3.40)\end{array}$ & 0.11 & $\begin{array}{l}13.08 \\
(3.28)\end{array}$ & $\begin{array}{l}13.16 \\
(3.30)\end{array}$ & 0.01 \\
\hline Currently married (\%) & 55.48 & 57.24 & $<0.01$ & 46.85 & 47.48 & 0.22 \\
\hline Currently employed (\%) & 64.51 & 62.74 & $<0.01$ & 45.30 & 43.28 & $<0.01$ \\
\hline Current smoker $(\%)$ & 32.25 & 28.43 & $<0.01$ & 21.41 & 19.24 & $<0.01$ \\
\hline Living in an MSA $(\%)$ & 80.59 & 84.04 & $<0.01$ & 80.98 & 83.62 & $<0.01$ \\
\hline White, non Hispanic (\%) & 61.27 & & & 56.35 & & \\
\hline African American, non Hispanic (\%) & 15.88 & & & 21.07 & & \\
\hline Native American Indian (\%) & 1.64 & & & 1.72 & & \\
\hline Asian $(\%)$ & 2.77 & & & 2.64 & & \\
\hline Hispanic $(\%)$ & 18.44 & & & 18.22 & & \\
\hline Born outside the US (\%) & 15.24 & & & 15.21 & & \\
\hline Sample size $(N)$ & 13993 & & & 18770 & & \\
\hline
\end{tabular}

Note: The $p$-values refer to student's $t$-test for continuous variables and to Chi-square tests for categorical variables. 
Operationally, the first-difference model for our purposes is specified as

$$
\Delta \mathrm{BMI}_{i}=\beta_{0}+\beta_{1} \Delta \text { Frequency }_{i}+\beta_{2} \Delta \text { Intensity }_{i}+\beta_{3} \Delta X_{i}^{\mathrm{TV}}+\Delta \varepsilon_{i}
$$

where $\Delta$ indicates change between waves, $X^{\mathrm{TV}}$ is a vector of time-varying control variables, the $\beta$ s are parameters to be estimated, and other variables are defined as above. The dependent variable in Equation (2) is the change in BMI between the two waves while the key explanatory variables are the changes in annual days of drinking and average number of drinks per episode between the two waves. The first-difference method eliminates the unobserved individual heterogeneity that was previously included in the disturbance term of Equation (1) and produces a consistent estimate for the effect of alcohol use on BMI (Wooldridge, 2001).

One limitation with our model is the potential reverse causality between BMI and alcohol use. Identification requires that change in alcohol use affects change in BMI and not vice versa. Yet certain individuals may in fact increase their drinking in an attempt to promote good health (e.g. little or no drinking to moderate drinking) or because of escalating alcohol abuse or dependence. It is also possible that changes in BMI could influence the frequency and intensity of alcohol use (e.g. as a response to obesity-related health problems). Because our modeling strategy cannot address reverse causality, we highlight this possibility as a limitation.

Even after taking first-differences, the BMI and alcohol use measures may still have some extreme outliers, which could significantly influence the regression results. Specifically, the percentage of the sample with changes in BMI, frequency of drinking, and intensity of drinking that were greater than two times the standard deviations from the mean were 5.41, 8.26, and 5.18\%. To minimize the influence of extreme outliers, we applied both standard OLS and robust regression (Li, 1985). The robust regression approach in Stata (StataCorp, 2005) is an iterative form of OLS whereby outlier observations are down-weighted in the final estimation. The technique first performs an initial screening to eliminate gross outliers (i.e. Cook's distance $>1$ ). An iterative regression approach then proceeds where Huber weights and bi-weights are assigned until convergence is achieved. Additional details on robust regression can be found in Berk (1990), Li (1985), and Rousseeuw and Leroy (1987). Although OLS and robust regression produced coefficient estimates that were similar in sign, magnitude, and significance, we report robust regression results in the tables because the overall fit was slightly better. The OLS results are available upon request.

\section{DATA}

We used data from Waves 1 and 2 of the NESARC to examine the effects of alcohol use on BMI among adults. The NESARC data set is appropriate for our analysis because it provides comprehensive data on body weight, height, and alcohol use measures over time and is nationally representative. Wave 1 was administered in 2001-2002, and Wave 2 was administered in 2004-2005. The NESARC compiled a representative sample of the US population, including both citizens and non-citizens, and the target population was civilian non-institutionalized individuals aged 18 and older residing in the US, including the District of Columbia, Alaska, and Hawaii. The US Bureau of the Census conducted the survey on behalf of the NIAAA.

A total of 43093 Wave 1 respondents were interviewed face-to-face through computer-assisted personal interviewing, with an overall survey response rate of $81 \%$. In Wave 2, the NESARC located and re-interviewed 34093 of the respondents that participated in the first Wave. Additional information on the sampling frame, instrumentation, and key findings of the NESARC are presented by Grant et al. (2003), Dawson et al. (2007), Ruan et al. (2008), and Grant et al. (2008). Because we employed a firstdifference model using longitudinal data, we included only those respondents who were surveyed in 
both waves. After excluding pregnant women and respondents who did not provide valid responses for all of the key variables in each wave, the final analysis sample included 32763 respondents.

\subsection{Measures}

Our key measure of body weight is the standard BMI, which is weight in kilograms divided by height in meters squared. BMI is a relatively reliable measure of body mass and has been used for decades to assign individuals to weight categories and to screen for possible health problems (WHO, 1995). Weight and height measures in the NESARC were self-reported, and Cawley (2001) has found that both men and women slightly underreport their actual BMI. If underreporting is present, however, it is likely to be consistent and stable across time for individuals. Underreporting in each wave will therefore have a less significant effect on longitudinal models than on cross-sectional models.

The two explanatory variables of interest are the frequency and intensity measures of alcohol use. Survey respondents were asked how often they drank alcohol in the past year. Ten response categories were included: every day, nearly every day, 3-4 times a week, 2 times a week, once a week, 2-3 times a month, once a month, 7-11 times in the past year, 2-6 times in the past year, and 1 or 2 times in the past year. All of these categorical responses were converted to days of use in the past year (i.e. frequency) using midpoints, with a range from 1.5 to 365 days. Abstainers were coded as drinking zero days in the past year.

Respondents were also asked the average number of drinks they consumed on days when they drank in the past year. This question formed our intensity measure of alcohol consumption, with a range from 1 to 36 in both waves. Again, abstainers were coded as consuming zero drinks. Finally, a dichotomous indicator for no drinking was constructed for alcohol abstainers in both waves.

Besides information on alcohol use, the NESARC provided detailed socioeconomic and demographic information on respondents. Most of the long list of potential control variables dropped out of the first-difference models because they were time-invariant. The following time-varying measures were included as change scores from Wave 1 to Wave 2: household income, number of people in household, marital status, employment status, tobacco use, living in a metropolitan statistical area (MSA), and mental health status. Because each of these time-varying controls is potentially endogenous (e.g. some psychotropic medications for mental health problems can cause weight gain), we estimated first-difference models both with and without these measures (full results available upon request).

\subsection{Descriptive statistics}

Table I presents descriptive statistics of the sample split by gender and survey wave for all the variables included in the subsequent models as well as a select number of time-invariant demographic variables. For men, the mean BMI in the analysis sample was $27.4(\mathrm{SD}=4.9)$ in Wave 1 and $27.9(\mathrm{SD}=5.1)$ in Wave 2. For women, the mean BMI was $27.0(\mathrm{SD}=6.3)$ in Wave 1 and $27.7(\mathrm{SD}=6.6)$ in Wave 2. Between Waves 1 and 2, average BMI increased by $1.8 \%$ for men $(p<0.01)$ and by $2.6 \%$ for women $(p<0.01)$, which is consistent with other findings in the literature.

For men, the mean frequency of alcohol consumption in the past year was 73.0 days in Wave 1 and increased slightly to 74.0 days in Wave 2 (not significant). Average number of drinks per episode (intensity) actually decreased slightly (not significant) from Wave 1 (2.15) to Wave 2 (2.11). About 28\% of men were alcohol abstainers in each wave. Women drank an average of about 36 days per year ( $p=0.02$ for time differences) and 1.2 drinks per episode (not significant). Just over $40 \%$ of women were alcohol abstainers in both waves. These statistics clearly show that frequency and intensity of alcohol consumption was much higher for men and that a greater percentage of women were abstainers.

The control variables display predictable patterns, with equivalent changes in direction for men and women (see Table I). Increases from Wave 1 to Wave 2 were evident for household income $(p<0.01)$, number of people in the household $(p<0.01)$, percentage married $(p<0.01$ for men, not significant for 
women), and percentage living in an MSA $(p<0.01)$. Decreases occurred for employment rate, smoking rate, and mental health status (all at $p<0.01$ ). Because education showed little change and the age increase was essentially identical for everyone in the sample, these change scores were not included in the first-difference models. The remaining control variables in Table I (i.e. race, ethnicity, born outside the US) dropped out of the first-difference models but were included along with all of the time-varying controls in the comparative cross-sectional specifications. ${ }^{2}$

For dichotomous control variables, we created three mutually exclusive and collectively exhaustive groups: no change from Wave 1 to Wave 2, positive change, and negative change. Dummy variables were included in the models for positive and negative change, with no change serving as the reference group.

\section{RESULTS}

Before discussing the main first-difference results, we present simple pooled cross-sectional estimates of BMI as a function of frequency and intensity of alcohol consumption, and a set of control variables (see Table II). Counter to expectations, days of drinking alcohol in the past year (frequency) is negative and significant $(p<0.01)$ for both genders. On the other hand, intensity of drinking (holding frequency constant) is positively related to BMI $(p<0.01)$ for both men and women. Drinking variables are likely confounded with important omitted (unobserved and unavailable) variables, which suggest that these results are not causal. Nevertheless, they provide a useful comparison to our preferred specifications.

Next, we offer simple descriptive evidence that the majority of individuals in the NESARC reported both BMI and alcohol consumption changes from Wave 1 to Wave 2 (see Table III). The fulfillment of this condition generates the variation required to identify the relationship between BMI and alcohol use in the first-difference models. Approximately $88 \%$ of men and $92 \%$ of women had any BMI change, and approximately half of those subjects reported a change of greater than $5 \%$ of their Wave 1 BMI. Frequency and intensity of alcohol consumption also display considerable variation from Wave 1 to Wave 2. For example, $71 \%$ of men and $60 \%$ of women experienced some change in drinking frequency or intensity while $43 \%$ of men and $36 \%$ of women experienced change in both frequency and intensity.

Our interpretation of the main regression results from first-difference estimation differs slightly from that of Table II because the key variables are change scores across two waves (see Table IV). It is useful to start with the constant terms, which represent the mean 3-year increase in BMI for adult drinkers who consume the same amount of alcohol (both frequency and intensity) in both waves. Men falling into this category gain an average of one-third of a BMI unit over three years while women gain more than half of a BMI unit. ${ }^{3}$

Moving to the main results, the coefficients on frequency and intensity in the augmented model are positive and statistically significant for men but not significant for women. More importantly, the magnitudes are small in all cases. For men, switching from abstinence to drinking twice a week - a substantial change in drinking behavior - leads to a negligible increase in BMI of approximately 0.032 BMI units. Raising the intensity by two glasses per episode (also a substantial change in drinking pattern) yields a slightly larger effect (approximately 0.058 BMI units). Including time-varying covariates and a dummy variable for abstainers in both waves does not appreciably change the estimated coefficients or standard errors on the alcohol use measures. In sum, the results partially confirm our first hypothesis that drinking frequency and intensity are positively and significantly related to weight gain over time, although the magnitudes have little practical importance (Ziliak and McClosky, 2008).

\footnotetext{
${ }^{2}$ We also ran the pooled cross-sectional models without the time-varying controls, and the key findings were almost identical.

${ }^{3}$ Refer to the results in the second pair of columns because they control for changes in other covariates; results are not sensitive to specification.
} 
Table II. Regression results for BMI using pooled cross-sectional data

\begin{tabular}{|c|c|c|}
\hline Independent variable $^{\mathrm{a}}$ & Men & Women \\
\hline \multicolumn{3}{|l|}{$O L S$ regression } \\
\hline Frequency: days of drinking alcohol, past year (in 100s) & $\begin{array}{c}-0.469^{* * *} \\
(0.030)\end{array}$ & $\begin{array}{c}-0.780^{* * *} \\
(0.046)\end{array}$ \\
\hline Intensity: average number of drinks per episode, past year & $\begin{array}{c}0.139^{* * *} \\
(0.013)\end{array}$ & $\begin{array}{c}0.112^{* * *} \\
(0.024)\end{array}$ \\
\hline Dummy variable for Wave 2 & $\begin{array}{c}0.451^{* * *} \\
(0.059)\end{array}$ & $\begin{array}{c}0.696^{* * *} \\
(0.065)\end{array}$ \\
\hline \multicolumn{3}{|l|}{ Robust regression $^{\mathrm{b}}$} \\
\hline Frequency: days of drinking alcohol, past year & $\begin{array}{c}-0.368^{* * *} \\
(0.027)\end{array}$ & $\begin{array}{c}-0.648^{* * *} \\
(0.041)\end{array}$ \\
\hline Intensity: average number of drinks per episode, past year & $\begin{array}{c}0.144^{* * *} \\
(0.012)\end{array}$ & $\begin{array}{c}0.135^{* * *} \\
(0.022)\end{array}$ \\
\hline Dummy variable for Wave 2 & $\begin{array}{c}0.345^{* * *} \\
(0.053)\end{array}$ & $\begin{array}{r}0.601^{* * *} * \\
(0.058)\end{array}$ \\
\hline
\end{tabular}

*** Significant at the $1 \%$ level.

${ }^{a}$ Control variables include household income, number of people in household, norm-based (SF-12) mental health scale, current marital status, age, years of schooling, employment status, smoking status, residing in an MSA, race, ethnicity, and born outside the US.

${ }^{b}$ Robust regression is an iterative form of OLS whereby outlier observations are down-weighted in the final estimation. The technique first performs an initial screening to eliminate gross outliers (i.e. Cook's distance $>1$ ). An iterative regression approach then proceeds where Huber weights and bi-weights are assigned until convergence is achieved. Additional details on robust regression can be found in Berk (1990), Li (1985), and Rousseeuw and Leroy (1987).

Table III. Changes in BMI and alcohol consumption variables from wave 1 to wave 2

\begin{tabular}{|c|c|c|c|c|}
\hline \multirow[b]{3}{*}{ Variables } & \multicolumn{4}{|c|}{ Changes from Wave 1 to Wave 2} \\
\hline & \multicolumn{2}{|c|}{ Men } & \multicolumn{2}{|c|}{ Women } \\
\hline & $N$ & Percent & $N$ & Percent \\
\hline \multicolumn{5}{|l|}{$B M I$} \\
\hline Any BMI change & 12296 & 87.87 & 17183 & 91.55 \\
\hline BMI change $>5 \%$ & 6256 & 44.71 & 10192 & 54.30 \\
\hline \multicolumn{5}{|l|}{ Alcohol consumption } \\
\hline Quit drinking & 1130 & 8.08 & 1686 & 8.98 \\
\hline Started drinking & 1030 & 7.36 & 1659 & 8.84 \\
\hline Changed drinking frequency, but not intensity & 2430 & 17.37 & 3337 & 17.78 \\
\hline Changed drinking intensity, but not frequency & 1506 & 10.76 & 1129 & 6.01 \\
\hline Changed both drinking frequency and intensity & 6069 & 43.37 & 6736 & 35.89 \\
\hline Changed neither drinking frequency nor intensity & 3988 & 28.50 & 7568 & 40.32 \\
\hline
\end{tabular}

For women, our main results show no statistically significant effect of changes in either drinking frequency or intensity on BMI, which is contrary to our second hypothesis. The estimated standard errors are quite small, suggesting that this result is not due to lack of power. Similarly, the magnitudes of the coefficients are generally smaller for women than for men. Predictions of typical changes in BMI are therefore lower for women than for men both because of the estimated coefficients and because of the plausible range of changes in drinking frequency and intensity.

Some of the other estimates in Table IV show interesting patterns. Household income has a positive and significant effect on BMI for women $(p<0.01)$, but the relationship is weaker $(p<0.10)$ for men. Marriage leads to higher BMI for both men and women - perhaps due to leaving the dating scene and devoting less effort to appearance - and becoming unmarried lowers BMI. The effects of employment changes are a bit different between men and women. Men and women who become employed and women who stop working have the largest BMI gains compared with those who have no change in 
Table IV. First-difference estimation of BMI change from wave 1 to wave 2

\begin{tabular}{|c|c|c|c|c|}
\hline \multirow[b]{2}{*}{ Independent variables } & \multicolumn{2}{|c|}{ Model 1} & \multicolumn{2}{|c|}{ Model 2} \\
\hline & Men & Women & Men & Women \\
\hline \multicolumn{5}{|l|}{ Alcohol consumption variables (changes between waves) } \\
\hline Frequency change: days of drinking alcohol, & 0.026 & -0.010 & $0.032^{*}$ & -0.005 \\
\hline past year (in 100s) & $(0.018)$ & $(0.027)$ & $(0.018)$ & $(0.027)$ \\
\hline $\begin{array}{l}\text { Intensity change: average number of drinks } \\
\text { per episode, past year }\end{array}$ & $(0.0068)$ & $\begin{array}{l}-0.013 \\
(0.013)\end{array}$ & $\begin{array}{c}0.0293^{3+*} \\
(0.0068)\end{array}$ & $\begin{array}{l}-0.002 \\
(0.013)\end{array}$ \\
\hline \multicolumn{5}{|l|}{ Control variables (changes between waves) } \\
\hline Household income in $\$ 10000 \mathrm{~s}$ & & & $\begin{array}{l}0.0061^{*} \\
(0.0037)\end{array}$ & $\begin{array}{r}0.0123^{* * *} \\
(0.0046)\end{array}$ \\
\hline \multirow[t]{2}{*}{ Number of persons in household } & & & 0.005 & 0.020 \\
\hline & & & $(0.014)$ & $(0.016)$ \\
\hline \multirow{2}{*}{ Norm-based (SF-12) mental health scale } & & & $0.0028^{* *}$ & $-0.0035^{* *}$ \\
\hline & & & $(0.0014)$ & $(0.0015)$ \\
\hline \multicolumn{5}{|l|}{ Current marital status (reference is no change) } \\
\hline Not married in Wave $1 \rightarrow$ married in Wave 2 & & & $\begin{array}{c}0.658^{* * *} \\
(0.076)\end{array}$ & $\begin{array}{r}0.667^{* * *} \\
(0.090)\end{array}$ \\
\hline Married in Wave $1 \rightarrow$ not married in Wave 2 & & & $\begin{array}{l}-0.43^{* * *} \\
(0.10)\end{array}$ & $\begin{aligned}-0.43^{* * *} & (0.10)\end{aligned}$ \\
\hline \multicolumn{5}{|l|}{ Employment status (reference is no change) } \\
\hline Not employed in Wave $1 \rightarrow$ employed in Wave 2 & & & $\begin{array}{l}0.342^{* * *} \\
(0.061)\end{array}$ & $\begin{array}{c}0.253^{* * *} \\
(0.065)\end{array}$ \\
\hline Employed in Wave $1 \rightarrow$ not employed in Wave 2 & & & $\begin{array}{c}0.011 \\
(0.056)\end{array}$ & $\begin{array}{c}0.374^{* * *} \\
(0.059)\end{array}$ \\
\hline \multicolumn{5}{|l|}{ Smoking status (reference is no change) } \\
\hline Non-smoker in Wave $1 \rightarrow$ smoker in Wave 2 & & & $\begin{array}{c}0.115 \\
(0.084)\end{array}$ & $\begin{array}{l}-0.08 \\
(0.12)\end{array}$ \\
\hline Smoker in Wave $1 \rightarrow$ non-smoker in Wave 2 & & & $\begin{array}{c}0.284^{* * * *} \\
(0.060)\end{array}$ & $\begin{array}{c}0.569^{* * * *} \\
(0.086)\end{array}$ \\
\hline \multicolumn{5}{|l|}{ Living in MSA (reference is no change) } \\
\hline Non-MSA in Wave $1 \rightarrow$ MSA in Wave 2 & & & $\begin{array}{l}-0.032 \\
(0.044)\end{array}$ & $\begin{array}{l}-0.082 \\
(0.050)\end{array}$ \\
\hline MSA in Wave $1 \rightarrow$ non-MSA in Wave 2 & & & $\begin{array}{c}0.051 \\
(0.048)\end{array}$ & $\begin{array}{l}-0.022 \\
(0.054)\end{array}$ \\
\hline Constant & $\begin{array}{c}0.398^{* * *} \\
(0.016)\end{array}$ & $\begin{array}{c}0.567^{* * * *} \\
(0.018)\end{array}$ & $\begin{array}{c}0.328^{* * *} \\
(0.021)\end{array}$ & $\begin{array}{c}0.483^{* * *} \\
(0.024)\end{array}$ \\
\hline
\end{tabular}

Notes: All specifications are estimated with the robust regression technique (StataCorp, 2005). The dependent variable is change in BMI from Wave 1 to Wave 2. *Significant at the $10 \%$ level; ${ }^{* *}$ significant at the $5 \%$ level; ${ }^{* * *}$ significant at the $1 \%$ level.

employment status. The former is consistent with Ruhm's $(2000,2005)$ findings on the macroeconomic effects of employment, and the latter may be related to household formation with less time available for structured exercise. The well-documented effect that quitting smoking leads to weight gain is found in these data as well. Men who quit smoking gain about a quarter of a BMI unit, and women, about a half. Finally, mental health changes show gender-specific and opposite effects on BMI. Specifically, men lose weight when mental health status declines whereas women gain weight.

Turning next to the additional hypotheses beyond our main models, adding quadratic terms for the two drinking variables did not change the main results (see Table V). For men, the coefficients on the linear term remained positive, significant (at $p<0.10$ for frequency and $p<0.01$ for intensity), and roughly the same magnitude. Interpreting the magnitudes, however, requires the quadratic terms. The negative quadratic term on frequency does not outweigh the linear term unless individuals change their frequency by 280 days in a year. A moderate change in drinking frequency is therefore positively related to weight gain, albeit at a small and diminishing rate. The quadratic term for intensity is positive but small enough that the effect is close to linear over the entire range of values in the data. The results are consistent across the two different specifications that control for additional variables. Hence, the main 
Table V. First-difference estimation of BMI Change from wave 1 to wave 2, adding quadratic forms of alcohol consumption variables

\begin{tabular}{|c|c|c|c|c|}
\hline \multirow[b]{2}{*}{ Independent variables } & \multicolumn{2}{|c|}{ Model 1} & \multicolumn{2}{|c|}{ Model 2} \\
\hline & Men & Women & Men & Women \\
\hline \multicolumn{5}{|l|}{ Alcohol consumption variables (changes between waves) } \\
\hline $\begin{array}{l}\text { Frequency change: days of drinking alcohol, } \\
\text { past year (in 100s) }\end{array}$ & $\begin{array}{c}0.025 \\
(0.018)\end{array}$ & $\begin{array}{l}-0.007 \\
(0.027)\end{array}$ & $\begin{array}{l}0.031^{*} \\
(0.018)\end{array}$ & $\begin{array}{l}-0.002 \\
(0.027)\end{array}$ \\
\hline Quadratic form of frequency change & $\begin{array}{c}-0.0132^{*} \\
(0.0073)\end{array}$ & $\begin{array}{c}0.007 \\
(0.010)\end{array}$ & $\begin{array}{c}-0.0136^{*} \\
(0.0073)\end{array}$ & $\begin{array}{c}0.005 \\
(0.010)\end{array}$ \\
\hline $\begin{array}{l}\text { Intensity change: average number of drinks } \\
\text { per episode, past year }\end{array}$ & $\begin{array}{c}0.0287^{* * * *} \\
(0.0069)\end{array}$ & $\begin{array}{l}-0.007 \\
(0.013)\end{array}$ & $\begin{array}{c}0.0321^{* * *} \\
(0.0069)\end{array}$ & $\begin{array}{c}0.004 \\
(0.013)\end{array}$ \\
\hline Quadratic form of intensity change & $\begin{array}{c}0.00129^{* * *} \\
(0.00050)\end{array}$ & $\begin{array}{c}0.0022^{* *} \\
(0.0011)\end{array}$ & $\begin{array}{r}0.00116^{* *} \\
(0.00050)\end{array}$ & $\begin{array}{l}0.0019^{*} \\
(0.0011)\end{array}$ \\
\hline \multicolumn{5}{|l|}{ Control variables (changes between waves) } \\
\hline Household income in $\$ 10000 \mathrm{~s}$ & & & $\begin{array}{c}0.0060 \\
(0.0037)\end{array}$ & $\begin{array}{c}0.0123^{* * *} \\
(0.0046)\end{array}$ \\
\hline Number of persons in household & & & $\begin{array}{c}0.005 \\
(0.014)\end{array}$ & $\begin{array}{c}0.020 \\
(0.016)\end{array}$ \\
\hline Norm-based (SF-12) mental health scale & & & $\begin{array}{c}0.0028^{* *} \\
(0.0014)\end{array}$ & $\begin{aligned}-0.0035^{* *} \\
(0.0015)\end{aligned}$ \\
\hline \multicolumn{5}{|l|}{ Current marital status (reference is no change) } \\
\hline Not married in Wave $1 \rightarrow$ married in Wave 2 & & & $\begin{array}{c}0.657^{* * *} \\
(0.076)\end{array}$ & $\begin{array}{c}0.665^{* * *} \\
(0.090)\end{array}$ \\
\hline Married in Wave $1 \rightarrow$ not married in Wave 2 & & & $\begin{array}{l}-0.43^{* * *} \\
(0.10)\end{array}$ & $\begin{array}{c}-0.42^{* * *} \\
(0.10)\end{array}$ \\
\hline \multicolumn{5}{|l|}{ Employment status (reference is no change) } \\
\hline Not employed in Wave $1 \rightarrow$ employed in Wave 2 & & & $\begin{array}{c}0.338^{* * *} \\
(0.062)\end{array}$ & $\begin{array}{c}0.250^{* * *} \\
(0.065)\end{array}$ \\
\hline Employed in Wave $1 \rightarrow$ not employed in Wave 2 & & & $\begin{array}{c}0.014 \\
(0.056)\end{array}$ & $\begin{array}{c}0.373^{* * *} \\
(0.059)\end{array}$ \\
\hline \multicolumn{5}{|l|}{ Smoking status (reference is no change) } \\
\hline Non-smoker in Wave $1 \rightarrow$ smoker in Wave 2 & & & $\begin{array}{l}0.106 \\
(0.084)\end{array}$ & $\begin{array}{l}-0.09 \\
(0.12)\end{array}$ \\
\hline Smoker in Wave $1 \rightarrow$ non-smoker in Wave 2 & & & $\begin{array}{c}0.285^{* * *} \\
(0.060)\end{array}$ & $\begin{array}{c}0.567^{* * *} \\
(0.086)\end{array}$ \\
\hline \multicolumn{5}{|l|}{ Living in MSA (reference is no change) } \\
\hline Non-MSA in Wave $1 \rightarrow$ MSA in Wave 2 & & & $\begin{array}{l}-0.032 \\
(0.044)\end{array}$ & $\begin{array}{l}-0.081 \\
(0.050)\end{array}$ \\
\hline MSA in Wave $1 \rightarrow$ non-MSA in Wave 2 & & & $\begin{array}{c}0.053 \\
(0.048)\end{array}$ & $\begin{array}{l}-0.022 \\
(0.054)\end{array}$ \\
\hline Constant & $\begin{array}{c}0.400^{* * *} \\
(0.017)\end{array}$ & $\begin{array}{c}0.560^{* * *} \\
(0.019)\end{array}$ & $\begin{array}{c}0.333^{* * * *} \\
(0.022)\end{array}$ & $\begin{array}{c}0.477^{* * *} \\
(0.024)\end{array}$ \\
\hline
\end{tabular}

Notes: All specifications are estimated with the robust regression technique (StataCorp, 2005). The dependent variable is change in BMI from Wave 1 to Wave $2 .{ }^{*}$ Significant at the $10 \%$ level; ${ }^{* *}$ significant at the $5 \%$ level; ${ }^{* * *}$ significant at the $1 \%$ level.

results for men continue to hold after including quadratic terms: increases in drinking frequency and intensity lead to a small increase in BMI over time relative to individuals who hold their drinking patterns constant, with slight non-linear effects. As before, none of the drinking variables in Table V was statistically significant for women.

To test our last hypothesis, we re-ran the core models (see Table IV) by age groups $(18-25,26-50$, and $51+$ ). For men, the coefficient for drinking intensity is larger in magnitude and more significant for the youngest age group while the effect of drinking frequency is relatively stable across cohorts. As before, none of the age-specific coefficient estimates for changes in drinking frequency and intensity was statistically significant for any group of women. These findings contradict our fourth hypothesis (viz., that the effect of alcohol use on body weight is greater for older individuals). All results are available from the authors upon request. 


\section{SENSITIVITY TESTS}

The core results presented in Table IV are insensitive to several important changes in specification and model. First, adding time-varying controls did not change the signs on the alcohol consumption variables and had little effect on either the magnitude or statistical significance. Because the results are insensitive to the inclusion of all intuitively and theoretically important observed time-varying variables, it is unlikely that including any of the unobserved time-varying variables in the estimation would substantially change the results.

Second, a few extreme outliers exist in both the dependent variable (change in BMI) and the primary explanatory variables (change in days of drinking alcohol and average number of drinks per episode). Extreme outliers are commonly defined as more than two standard deviations away from the mean. In our analysis sample, $485(3.5 \%)$ men and $1286(6.9 \%)$ women experienced BMI changes that would be considered outliers by this definition. Furthermore, $1568(11.2 \%)$ men and $1139(6.1 \%)$ women demonstrated alcohol frequency changes that could be considered outliers, whereas $1200(8.6 \%)$ men and $496(2.6 \%)$ women could be considered outliers for intensity. While some of the largest values seem implausible to us and may be the result of reporting errors (i.e. $>|10|$ for BMI change, $>|100|$ for frequency change, or $>|4|$ for change in intensity), they may in fact represent real changes. Unfortunately, it is difficult to verify the results one way or the other without obtaining more information on the subjects. Therefore, rather than arbitrarily trim the data, we ran robust regression as an alternative to standard OLS. When running the core models with OLS instead of robust regression, the only meaningful difference was the loss of significance on drinking frequency for men (see Appendix Table AI).

Finally, we recoded the drinking frequency measure into the original 11 drinking categories ranging from no alcohol consumption during the past year (0) to daily drinking (10). The change scores from Wave 1 to Wave 2 now range from -10 to 10 instead of -365 to 365 . This adjustment served to compress a skewed distribution, minimize the influence of potential reporting errors at the higher values, reduce measurement error, and determine whether such a change had an appreciable effect on the core results. As reported in Table AII, drinking frequency is now significant at the $1 \%$ level for men (the quantitative effects are not meaningful because the category values are arbitrary) and the effect of drinking intensity remains statistically significant and small in magnitude. As in Table IV, neither drinking frequency nor intensity is significant for women.

\section{DISCUSSION}

The main findings of this research can be summarized as follows. First, the frequency of alcohol consumption (i.e. days of drinking alcohol in the past year) has a very small positive and marginally statistically significant effect on BMI for men. The intensity of alcohol use (i.e. average number of drinks per episode) is also positive and statistically significant for men, with a relatively larger effect size (yet quantitatively inconsequential) and greater statistical significance. The frequency and intensity effects are slightly non-linear but remain positive for nearly all plausible values of changes in drinking patterns. These results offer weak support for two of our four hypotheses. The trivial effect sizes, however, suggest that changes in alcohol consumption alone are unlikely to cause wide swings in body weight for men.

We surmise that one of the main reasons for the relatively small effect sizes is compensating behavior by alcohol consumers. Numerous studies in the clinical (Boffetta and Garfinkel, 1990; Marmot and Brunner, 1991; Doll et al., 1994; Gunzerath et al., 2004) and economics (Mullahy and Sindelar, 1993; French and Zarkin, 1995; Heien, 1996; Zarkin et al., 1998) literature demonstrate the benefits of moderate drinking. It is conceivable that moderate drinking is a marker for moderate living. Perhaps these individuals adjust their behaviors in other areas (e.g. better diet, more exercise) when they increase their alcohol consumption so as to preserve their moderate lifestyle (French and Zavala, 2007; French et al., in press). If true, then any relatively large changes in alcohol consumption would lead to little or no change in BMI because individuals adjust their diet, exercise, and other behaviors to counteract potential weight gain. 
Second, we find no effect of changes in drinking frequency or intensity on BMI for women. We do not have a convincing explanation for the lack of significance for women as both the literature and our third hypothesis imply the opposite. Table I, however, shows that a sizable minority of females was abstinent in both waves of the NESARC and that the mean change in intensity was not significantly different from zero. In addition, other studies in the literature have found counterintuitive results (e.g. heavy drinking is positively associated with earnings) pertaining to alcohol use among women (Kenkel and Ribar, 1994; Mullahy and Sindelar, 1996, 1997).

Third, we hypothesized that any effects of alcohol consumption on BMI would be more pronounced for older adults (age 51 and older). We found instead that the effect of drinking intensity on BMI for men is actually greater for younger adults (age 18-25). Most of the alcohol coefficient estimates for older adults are relatively small and not significantly different from zero. Perhaps these findings are driven by the greater variability in BMI and alcohol consumption among younger adults.

Finally, our first-difference results highlight the extent of potential bias that may be present with singleequation estimates from cross-sectional data. The pooled cross-sectional estimates in Table II are often different in sign and significance, and much larger in magnitude relative to the preferred first-difference results in Table IV. For example, relying only on the estimates in Table II, one might incorrectly conclude that drinking frequency is negatively related to changes in BMI. Panel data methods, such as the firstdifference technique, allow us to control for a myriad of unobserved time-invariant factors related to both drinking and body weight that could bias the coefficient estimates in cross-sectional models.

Despite the technical appeal of first-difference methods, this research has limitations that must be acknowledged and understood before the findings can be properly interpreted. First, the height and weight of the NESARC respondents was self-reported. Previous research (Cawley, 2004; Cawley and Danzinger, 2004; Himes et al., 2005) has determined that individuals tend to over-estimate height and underestimate weight leading to downwardly biased estimates of BMI. The ideal dataset would include objective physical measurements of height, fatness, and muscle. The presence of such misreporting within our sample is impossible to determine, but if it is present, the likely result would be even lower coefficient estimates.

Second, alcohol consumption measures were self-reported. While this issue cannot be completely resolved, the published literature on this topic indicates that self-reported alcohol consumption measures are reliable for use in statistical analyses (Friesema et al., 2004; Lintonen et al., 2004). Self-reported alcohol consumption suffers less from misreporting when closed questions are utilized, as is the case in the NESARC (Lintonen et al., 2004, http://www.niaaa.nih.gov/). Given that self-reporting of recent alcohol use is a reliable method used by the NIAAA and other national surveys (e.g. NHIS, NHANES, NHSDA), we have confidence in the estimated relationships. To the extent they exist, discrepancies across surveys in obesity rates are probably due to different populations sampled by each survey. The NESARC utilizes a population sample of adults aged 18 and over while the NHANES uses a sample population of 20 to 74-year-old adults. The 18 to 19-year-old age group consistently has the lowest obesity rates in the adult population, causing the NESARC's obesity rates to be lower than previous estimates ( $25 \%$ obesity rate in the $18+$ population and $30.6 \%$ obesity rate in the population aged $20-74)$.

Third, frequency of alcohol consumption during the past year was reported within 10 categories rather than a point estimate. To transform the categorical values of drinking frequency into a continuous measure, we took the mid-point of each range and then extrapolated (e.g. 3-4 times a week $=3.5(52)=182$ times per year). This transformation of the data potentially introduces measurement error, and therefore bias, into our analysis. The extent of this potential bias is not known. Nevertheless, in sensitivity analyses we examined the original frequency categories in ordered increments, where we expect the induced measurement error to be less severe, and our main findings are relatively unchanged.

In conclusion, current scientific and policy debates over the alarming rise in average body weight among Americans generally focus on diet and exercise. Yet given the popularity and relatively high caloric content of most alcoholic beverages, alcohol consumption would seem to represent another potential target area in the battle against obesity. The findings presented in this paper, however, indicate a statistically significant yet quantitatively immaterial link between increasing alcohol use and weight 
gain among men. Moreover, contrary to our expectations, alcohol use does not appear to be a risk factor for weight gain among women and older adults. Perhaps federal and state governments should continue to use their influence over alcohol advertising, distribution, taxes, and prices to combat the most visible risks associated with excessive alcohol consumption, such as health problems, motor vehicle accidents, and alcoholism (Morgan, 1994; Mann et al., 2003; Mandayam et al., 2004; Beilin et al., 1996; Puddey et al., 1999; Puddey and Beilin, 2006; Manning et al., 1989). Any spillover effects of these policies in lowering the average rates of overweight and obesity in the US is likely to be minimal at best.

\section{ACKNOWLEDGEMENTS}

Financial assistance for this study was provided by the National Institute on Alcohol Abuse and Alcoholism (R01-AA13167, RO1-AA-015695). We gratefully acknowledge the informative comments received from seminar participants at the 2006 European Conference on Health Economics and the 2005 Addiction Health Services Research Conference, and especially those of Will Manning of the University of Chicago. We are also indebted to Shay Klevay, William Russell, and Carmen Martinez for editorial and administrative assistance. The authors are entirely responsible for the research and results reported in this paper, and their position or opinions do not necessarily represent those of the University of Miami, the University of Michigan, or the National Institute on Alcohol Abuse and Alcoholism. The authors wish to state that there are no potential conflicts of interest.

\section{APPENDIX A}

First-difference estimation of BMI change from wave 1 to wave 2 - OLS is given in Table AI and that using categorical change in drinking frequency is given in Table AII.

Table AI. First-difference estimation of BMI change from wave 1 to wave 2 - OLS

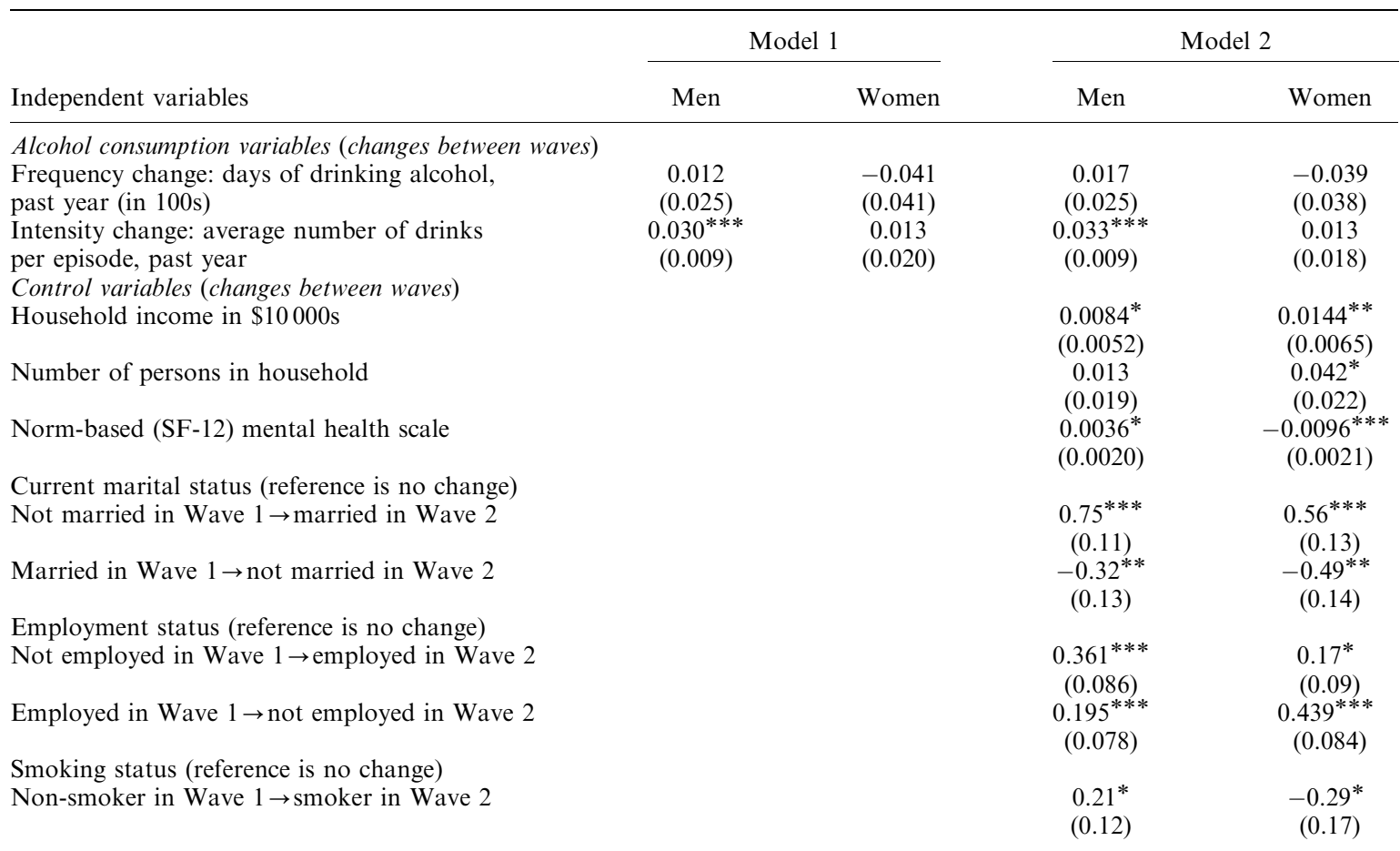


Table AI. Continued

\begin{tabular}{|c|c|c|c|c|}
\hline \multirow[b]{2}{*}{ Independent variables } & \multicolumn{2}{|c|}{ Model 1} & \multicolumn{2}{|c|}{ Model 2} \\
\hline & Men & Women & Men & Women \\
\hline Smoker in Wave $1 \rightarrow$ non-smoker in Wave 2 & & & $\begin{array}{c}0.403 * * * \\
(0.084)\end{array}$ & $\begin{array}{c}0.67^{* * *} \\
(0.12)\end{array}$ \\
\hline Living in MSA (reference is no change) & & & & \\
\hline Non-MSA in Wave $1 \rightarrow$ MSA in Wave 2 & & & $\begin{array}{l}-0.073 \\
(0.061)\end{array}$ & $\begin{array}{l}-0.108 \\
(0.071)\end{array}$ \\
\hline MSA in Wave $1 \rightarrow$ non-MSA in Wave 2 & & & $\begin{array}{c}0.107 \\
(0.068)\end{array}$ & $\begin{array}{l}-0.017 \\
(0.076)\end{array}$ \\
\hline Constant & $0.0491^{* * *}$ & $0.707^{* * *}$ & $0.376^{* * *}$ & $0.620^{* * *}$ \\
\hline & $(0.022)$ & $(0.025)$ & $(0.030)$ & $(0.034)$ \\
\hline
\end{tabular}

Notes: All specifications are estimated with the robust regression technique (StataCorp, 2005). The dependent variable is change in BMI from Wave 1 to Wave $2 .{ }^{*}$ Significant at the $10 \%$ level; ${ }^{* *}$ significant at the $5 \%$ level; ${ }^{* * *}$ significant at the $1 \%$ level.

Table AII. First-difference estimation of BMI change from wave 1 to wave 2 using categorical change in drinking frequency

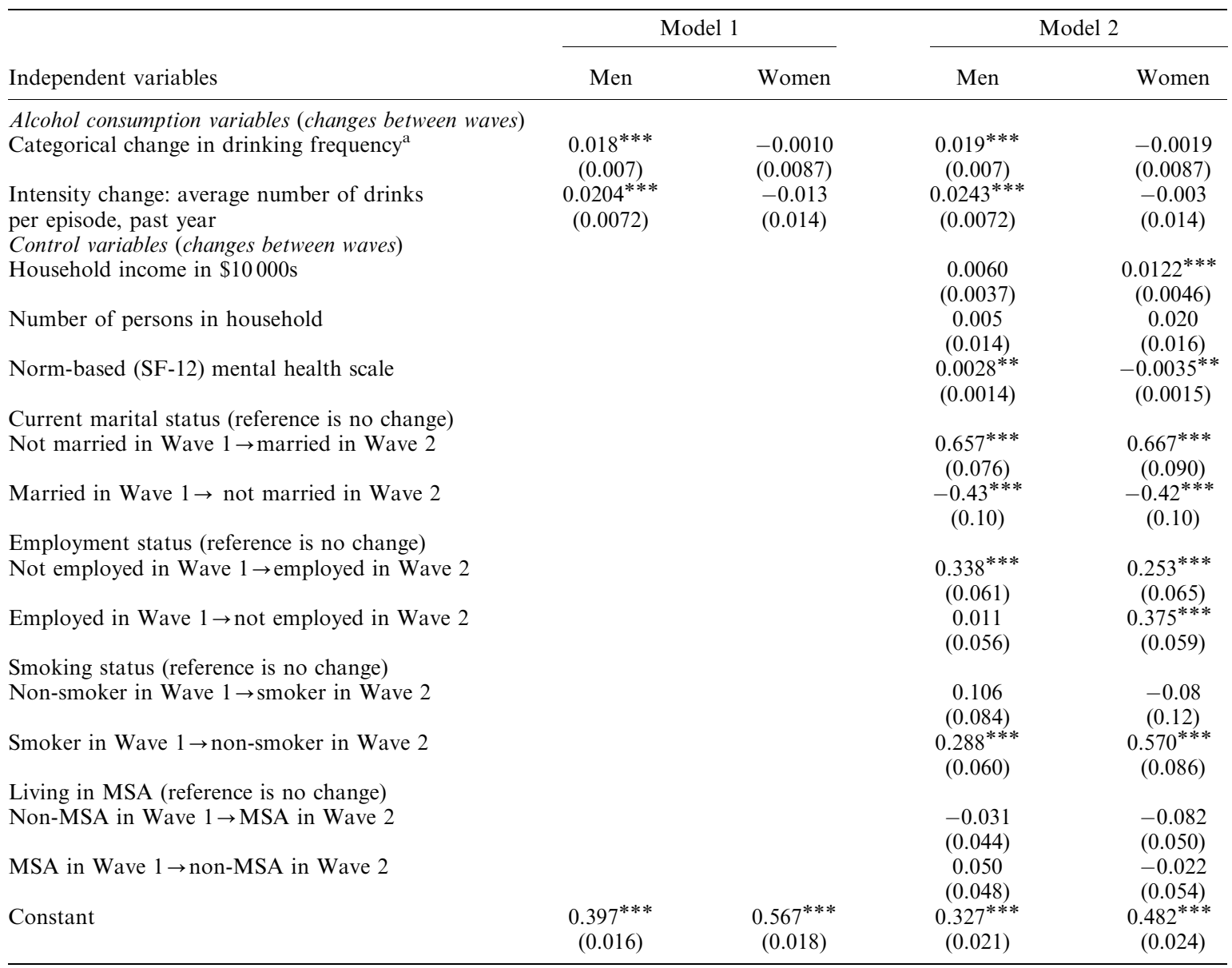

Notes: All specifications are estimated with the robust regression technique (StataCorp, 2005). The dependent variable is change in BMI from Wave 1 to Wave 2. *Significant at the $10 \%$ level; ${ }^{* *}$ significant at the $5 \%$ level; *** significant at the $1 \%$ level. ${ }^{\mathrm{a}}$ Categorical change in drinking frequency ranges from -10 to 10 because 0 corresponds to no drinking during the past year and 10 corresponds to drinking every day. 


\section{REFERENCES}

Averett S, Korenman S. 1996. The economic reality of the beauty myth. Journal of Human Resources 31: 304-330.

Baraona E, Abittan CS, Dohmen K, Moretti M, Pozzato G, Chayes ZW, Schaefer C, Lieber CS. 2001. Gender differences in pharmacokinetics of alcohol. Alcoholism: Clinical and Experimental Research 25: $502-507$.

Beilin LJ, Puddey IB, Burke V. 1996. Alcohol and hypertension - kill or cure? Journal of Human Hypertension 10: S1-S5.

Berk RA. 1990. A primer on robust regression. In Modern Methods of Data Analysis, Fox J, Long JS (eds). Sage: Newbury Park, CA; 292-324.

Breslow RA, Smothers BA. 2005. Drinking patterns and body mass index in never smokers: National Health Interview Survey, 1997-2001. American Journal of Epidemiology 161: 368-376.

Boffetta P, Garfinkel L. 1990. Alcohol drinking and mortality among men enrolled in an American Cancer Society prospective study. Epidemiology 1: 342-348.

Casbon TS, Curtin JJ, Lang AR, Patrick CJ. 2003. Deleterious effects of alcohol intoxication: diminished cognitive control and its behavioral consequences. Journal of Abnormal Psychology 112: 476-487.

Cawley J. 1999. Obesity and Addiction. Ph.D. Dissertation, University of Chicago.

Cawley J. 2001. Body weight and dating behaviors of young adolescents. In Social Awakening: Adolescent Behavior as Adulthood Approaches, Michael RT (ed.). Russell Sage: New York; 174-198.

Cawley J. 2003. What explains race and gender differences in the relationship between obesity and wages? Gender Issues 21: 30-49.

Cawley J. 2004. The impact of obesity on wages. Journal of Human Resources 39: 451-474.

Cawley J, Danzinger S. 2004. Obesity as a barrier to the transition from welfare to work. National Bureau of Economic Research Working Paper No. 10508.

Chou SY, Grossman M, Saffer H. 2002. An economic analysis of adult obesity: results from the Behavioral Risk Factor Surveillance System. National Bureau of Economic Research Working Paper No. 9247.

Cordain L, Bryan ED, Melby CL, Smith MJ. 1997. Influence of moderate daily wine consumption on body weight regulation and metabolism in healthy free-living males. Journal of the American College of Nutrition 16: 134-139.

Cordain L, Melby CL, Hamamoto AE, O’Neill DS, Cornier MA, Barakat HA, Israel RG, Hill JO. 2000. Influence of moderate chronic wine consumption on insulin sensitivity and other correlates of syndrome X in moderately obese women. Metabolism 49: 1473-1478.

Costa DL, Steckel RH. 1995. Long-term trends in health, welfare, and economic growth in the United States. National Bureau of Economic Research Historical Paper No. 76.

Cutler DM, Glaeser EL, Shapiro JM. 2003. Why have Americans become more obese? Journal of Economic Perspectives 17: 93-118.

Dawson DA, Goldstein RB, Grant BF. 2007. Rates and correlates of relapse among individuals in remission from DSM-IV alcohol dependence: a 3-year follow-up. Alcoholism: Clinical and Experimental Research 31: 2036-2045.

de Castro JM. 2000. Eating behavior: lessons from the real world of humans. Nutrition 16: 800-813.

Doll R, Peto R, Hall E, Wheatley K, Gray R. 1994. Mortality in relation to consumption of alcohol: 13 years' observations on male British doctors. British Medical Journal 309: 911-918.

Field M, Mogg K, Bradley BP. 2005. Alcohol increases cognitive biases for smoking cues in smokers. Psychopharmacology 180: 63-72.

Finkelstein EA, Fiebelkorn IC, Wang G. 2003. National medical spending attributable to overweight and obesity: how much, and who's paying? Health Affairs Web Exclusives 14: W3-219-W3-226.

Flegal KM, Carroll MD, Odgen CL, Johnson CL. 2002. Prevalence and trends in obesity among US adults, 1999-2000. Journal of the American Medical Association 288: 1723-1727.

Flegal KM, Graubard BI, Williamson DF, Gail MH. 2005. Excess deaths associated with underweight, overweight, and obesity. Journal of the American Medical Association 293: 1861-1867.

Fogel RW. 1994. Economic growth, population theory, and physiology: the bearing of long-term processes on the making of an economy policy. American Economic Review 84: 369-395.

Fonda S, Fultz N, Jenkins K, Wheeler L, Wray L. 2004. Relationship of body mass and net worth for retirementaged men and women. Research on Aging 26: 153-176.

French MT. 2002. Physical appearance and earnings: further evidence. Applied Economics 34: 569-572.

French MT, Popovici I. 2008. That instrument is lousy! In search of agreement when using instrumental variables estimation in substance use research. Working Paper, University of Miami, Coral Gables.

French MT, Popovici I, Maclean JC. Do alcohol consumers exercise more? Findings from a national survey. American Journal of Health Promotion; in press. 
French MT, Zarkin GA. 1995. Is moderate alcohol use related to wages? Evidence from four worksites. Journal of Health Economics 14: 319-344.

French MT, Zavala SK. 2007. The health benefits of moderate drinking revisited: alcohol use and self-reported health status. American Journal of Health Promotion 21: 484-491.

Frezza M, Di Padova C, Pozzoto G, Terpin M, Baraona E, Lieber CS. 1990. High blood alcohol levels in women: the role of decreased gastric alcohol dehydrogenase activity and first-pass metabolism. New England Journal of Medicine 322: 95-99.

Friesema IH, Veenstra MY, Zwietering PJ, Knottnerus JA, Garretsen HF, Lemmens PH. 2004. Measurement of lifetime alcohol intake: utility of a self-administered questionnaire. American Journal of Epidemiology 159: 809-817.

Goldbloom DS, Naranjo CA, Bremner KE, Hicks LK. 1992. Easting disorders and alcohol abuse in women. British Journal of Addiction 87: 913-920.

Grant BF, Goldstein RB, Chou SP, Huang B, Stinson FS, Dawson DA, Saha TD, Smith SM, Pulay AJ, Pickering RP, Ruan WJ, Compton WM. 2008. Sociodemographic and psychopathologic predictors of first incidence of DSM-IV substance use, mood and anxiety disorders: results from the Wave 2 National Epidemiologic Survey on Alcohol and Related Conditions. Molecular Psychiatry 1-16, Advance Online Publication, April 22, doi:10.1038/mp.2008.41.

Grant BF, Kaplan K, Shephard J, Moore T. 2003. Source and Accuracy Statement for Wave 1 of the 2001-2002 National Epidemiologic Survey on Alcohol and Related Conditions. National Institute on Alcohol Abuse and Alcoholism (NIAAA), Bethesda, MD.

Gruber J, Frakes M. 2006. Does falling smoking lead to rising obesity? Journal of Health Economics 25: $183-197$.

Gruchow HW, Kobocinski KA, Barboriak JJ, Scheller J. 1985. Alcohol consumption, nutrient intake and relative body weight among US adults. The American Journal of Clinical Nutrition 42: 289-295.

Gunzerath L, Faden V, Zakhari S, Warren K. 2004. National Institute on Alcohol Abuse and Alcoholism report on moderate drinking. Alcoholism: Clinical and Experimental Research 28: 829-847.

Heien DM. 1996. Do drinkers earn less? Southern Economic Journal 63: 60-68.

Hendrie HC, Gao SJ, Hall KS, Hui SL, Unverzagt FW. 1996. The relationship between alcohol consumption, cognitive performance, and daily functioning in an urban sample of older black Americans. Journal of the American Geriatrics Society 44: 1158-1165.

Himes JH, Hannan P, Wall M, Neumark-Sztainer D. 2005. Factors associated with errors in self-reports of stature, weight, and body mass index in Minnesota adolescents. Annals of Epidemiology 15: 272-278.

Hommer DW, Momenan R, Kaiser E, Rawlings RR. 2001. Evidence for a gender-related effect of alcoholism on brain volumes. American Journal of Psychiatry 158: 198-204.

Hupkens CLH, Knibbe RA, Drop MJ. 1993. Alcohol consumption in the European community: uniformity and diversity in drinking patterns. Addiction 88: 1391-1404.

Ippolito PM, Mathios AD. 1995. Information and advertising: the case of fat consumption in the United States. American Economic Review 85: 91-95.

Istvan J, Murray R, Voelker H. 1995. The relationship between patterns of alcohol consumption and body weight. Lung Health Study Research Group. International Journal of Epidemiology 24: 543-546.

Kenkel DS, Ribar DC. 1994. Alcohol consumption and young adults socioeconomic status. Brookings Papers on Economic Activity: Microeconomics 1: 119-175.

Lakdawalla D, Philipson TJ. 2002. The growth of obesity and technological change: a theoretical and empirical examination. National Bureau of Economic Research Working Paper No. 8946.

Leibowitz SF. 2007. Overconsumption of dietary fat and alcohol: mechanisms involving lipids and hypothalamic peptides. Physiology and Behavior 91: 513-521.

Li G. 1985. Robust regression. In Exploring Data Tables, Trends, and Shapes, Hoaglin DC, Mosteller F, Tukey JW (eds). Wiley: New York.

Lieber CS. 2000. Ethnic and gender differences in ethanol metabolism. Alcoholism: Clinical and Experimental Research 24: 417-418.

Lintonen T, Ahlstrom S, Metso L. 2004. The reliability of self-reported drinking in adolescence. Alcohol and Alcoholism 39: 362-368.

Mandayam S, Jamal MM, Morgan TR. 2004. Epidemiology of alcoholic liver disease. Seminars in Liver Disease 24: 217-232.

Mann RE, Smart RG, Govoni R. 2003. The epidemiology of alcoholic liver disease. Alcohol Research and Health 27: 209-219. 
Manning WG, Keeler EB, Newhouse JP, Sloss EM, Wasserman J. 1989. The taxes of sin: do smokers and drinkers pay their way? Journal of the American Medical Association 261: 859-866.

Marmot M, Brunner E. 1991. Alcohol and cardiovascular disease: the status of the U shaped curve. British Medical Journal 303: 565-568.

McGinnis JJ, Foege WH. 1993. Actual causes of death in the United States. Journal of the American Medical Association 270: 2207-2212.

Mokdad AH, Marks JS, Stroup DF, Gerberding JL. 2004. Actual causes of death in the United States, 2000. Journal of the American Medical Association 291: 1238-1245.

Mokdad AH, Serdula MK, Dietz WH, Bowman BA, Marks JS, Kaplan JP. 1999. The spread of the obesity epidemic in the United States, 1991-1998. Journal of the American Medical Association 282: 1519-1522.

Morgan MY. 1994. The prognosis and outcome of alcoholic liver disease. Alcohol and Alcoholism Supplement 2: 335-343.

Mullahy J, Sindelar J. 1993. Alcoholism, work, and income. Journal of Labor Economics 11: 494-520.

Mullahy J, Sindelar J. 1996. Employment, unemployment, and problem drinking. Journal of Health Economics 15: 409-434.

Mullahy J, Sindelar J. 1997. Women and work: tipplers and teetotalers. Health Economics 6: 533-537.

Must A, Spadano J, Coakley EH, Field AE, Colditz G, Dietz WH. 1999. The disease burden associated with overweight and obesity. Journal of the American Medical Association 282: 1523-1529.

Naik NY, Moore MJ. 1996. Habit formation and intertemporal substitution in individual food consumption. Review of Economic Statistics 78: 321-328.

National Institute on Alcohol Abuse and Alcoholism (NIAAA). 2009. Accessed on April 9, from http:// www.niaaa.nih.gov/Resources/DatabaseResources/QuickFacts/AlcoholDependence/abusdep2.htm.

Ogden CL, Carroll MD, Curtin LR, McDowell MA, Tabak CJ, Flegal KM. 2006. Prevalence of overweight and obesity in the United States, 1999-2004. Journal of the American Medical Association 295: 1549-1555.

Philipson TJ, Posner RA. 2003. The long-run growth in obesity as a function of technological change. Perspectives in Biology and Medicine 46: S87-S107.

Puddey IB, Beilin LJ. 2006. Alcohol is bad for blood pressure. Clinical and Experimental Pharmacology and Physiology 33: 847-852.

Puddey IB, Rakic V, Dimmitt SB, Beilin LJ. 1999. Influence of pattern of drinking on cardiovascular disease and cardiovascular risk factors - a review. Addiction 94: 649-663.

Ramchandani VA, Bosron WF, Li TK. 2001. Research advances in ethanol metabolism. Pathologie Biologie 49: 676-682.

Rashad I. 2006. Structural estimation of caloric intake, exercise, smoking, and obesity. Quarterly Review of Economics and Finance 46: 268-283.

Rashad I, Grossman M, Chou SY. 2006. The super size of America: an economic estimation of body mass index and obesity in adults. Eastern Economic Journal 32(1): 133-148.

Robbins CA, Martin SS. 1993. Gender, styles of deviance, and drinking problems. Journal of Health and Social Behavior 34: 302-321.

Robins PK, Homer JF, French MT. 2009. Beauty and the labor market: a further examination. Working Paper, University of Miami, Coral Gables.

Rousseeuw PJ, Leroy AM. 1987. Robust Regression and Outlier Detection. Wiley: New York.

Ruan WJ, Goldstein RB, Chou SP, Smith SM, Saha TD, Pickering RP, Dawson DA, Huang B, Stinson FS, Grant BF. 2008. The Alcohol Use Disorder and Associated Disabilities Interview Schedule-IV (AUDADIS-IV): reliability of new psychiatric diagnostic modules and risk factors in a general population sample. Drug and Alcohol Dependence 92: 27-36.

Ruhm CJ. 2000. Are recessions good for your health? Quarterly Journal of Economics 115: 617-650.

Ruhm CJ. 2005. Healthy living in hard times. Journal of Health Economics 24: 341-363.

StataCorp. 2005. Stata Statistical Software: Release 9. StataCorp LP: Texas.

Stewart SH, Brown CG, Devoulyte K, Theakston J, Larsen SE. 2006. Why do women with alcohol problems binge eat? Exploring connections between binge eating and heavy drinking in women receiving treatment for alcohol problems. Journal of Health Psychology 11: 409-425.

US Department of Health and Human Services (USDHHS). 2001. The Surgeon General's Call to Action to Prevent and Decrease Overweight and Obesity. Public Health Office, Office of the Surgeon General, Department of Health and Human Services: Rockville, MD.

Wilsnack RW, Vogeltanz ND, Wilsnack SC, Harris TR. 2000. Gender differences in alcohol consumption and adverse drinking consequences: cross-cultural patterns. Addiction 95: 251-265.

Wooldridge JM. 2001. Econometric Analysis of Cross Section and Panel Data. MIT Press: Cambridge, MA. 
World Health Organization (WHO). 1995. Physical Status: The Use and Interpretation of Anthropometry. WHO Technical Report Series, Geneva, Switzerland.

Zarkin GA, French MT, Mroz T, Bray JW. 1998. Alcohol use and wages: new results from the National Household Survey on Drug Abuse. Journal of Health Economics 17: 53-68.

Ziliak ST, McClosky DN. 2008. The Cult of Statistical Significance: How the Standard Error Cost us Jobs, Justice, and Lives. The University of Michigan Press: Ann Arbor, MI. 